Patients with low vitamin E level $(n=4)$ all had a normal vitamin E:cholesterol ratio. Thus, in accordance with the ESPGHAN guidance1 these patients had a normal vitamin $\mathrm{E}$ status. In this subgroup, if the serum vitamin E level alone had been measured these patients would have undergone PN adjustments which were not clinically indicated.

Hepatic profile was performed in 94\% $(n=30)$ and derangement was noted in $41 \%(n=13)$. In this sub-cohort, the mean vitamin E, cholesterol levels and vitamin E:cholesterol ratio were similar to the entire cohort, see table 2 . One patient demonstrated cholestasis (raised ALP and GGT) and associated abnormal synthetic liver function (raised PT time, normal albumin) with a normal vitamin E:cholesterol ratio (and cholesterol level) but high vitamin E level; thus, deficiency would not have been missed.

No patients had a low vitamin E:cholesterol ratio. These results are not keeping with other studies. This could be attributable to the small study size. Also, as increased age is a risk factor for elevated lipid levels, this paediatric only population could be a limitation of this study.

Conclusion In accordance with the ESPGHAN guidance this study demonstrated the utility of measuring the vitamin E:cholesterol ratio to define the vitamin $\mathrm{E}$ status amongst the home PN population with potentially associated economical and logistical benefit.

\section{P10 CASE REPORT: MUCINOUS ADENOCARCINOMA OF COLON IN AN ADOLESCENT}

Suchandra Pande, Nitin Patwardhan. Leicester Royal Infirmary

\subsection{6/flgastro-2021-bspghan.21}

Introduction/Background Colorectal carcinoma (CRC) is commonly found in adults. CRC in the paediatric population is extremely rare.

Paediatric patients with CRC present with non-specific symptoms (abdominal pain, obstructive symptoms, anaemia) and may have an abdominal mass - similar to the presentation in adults.

Primary GI malignancies constitute $\sim 2 \%$ of paediatric neoplasms. On the other hand, paediatric CRC comprises a small proportion of all CRC. Diagnosis of CRC in the paediatric population is usually delayed due to its rarity and therefore low index of suspicion. CRC in children can be associated with Polyposis Syndromes and inflammatory bowel disease (IBD). Sporadic CRC in children is rare.

We report a case of mucinous adenocarcinoma of the colon in a 17-year old female who presented with abdominal pain, altered bowel habit, anaemia and developed bowel perforation while awaiting colonoscopy. Diagnosis was confirmed on histology of resected caecum and ascending colon.

Case report A 17-year old adolescent girl was admitted under general paediatric team with abdominal pain, blood in stool, feeling tired, possible low-grade fever. She was noted to have severe anaemia ( $\mathrm{Hb} 47 \mathrm{~g} / \mathrm{L}$ ); other blood results unremarkable. She was treated with intravenous antibiotics and received blood transfusion. Her abdominal pain and diarrhoea improved. There is no family history of any bowel disorder. Her stool sample culture was negative. Calprotectin was $>1000$ microgram/gm raising suspicion of IBD. Ultrasound abdomen showed 'some faecal loading in caecum and ascending colon', otherwise unremarkable. She was discharged with plan for colonoscopy within 4 weeks.

\begin{tabular}{|c|c|}
\hline Histology & $\begin{array}{l}\text { Poorly differentiated signet ring cell/mucinous adenocarcinoma } \\
\text { with localised tumour perforation and serosal involvement; } \\
\text { MMR protein proficient }\end{array}$ \\
\hline TNM8 Staging & pT4a pN2b, V1, R0 \\
\hline $\begin{array}{l}\text { KRAS, NRAS, BRAF } \\
\text { mutation }\end{array}$ & Not detected \\
\hline CEA & $2 \mathrm{ug} / \mathrm{L}(0-5)$ \\
\hline Post-Surgery CT scan & $\begin{array}{l}\text { No evidence of mediastinal or axillary node involvement; no } \\
\text { pulmonary or liver metastases. }\end{array}$ \\
\hline
\end{tabular}

Three weeks later she re-attended with acute severe abdominal pain and was re-admitted under gastroenterology team. She had an extremely tender abdomen with guarding in right iliac fossa. CT abdomen showed localised perforation in ascending colon with a mass and extensive fat stranding. She underwent an emergency laparotomy, right hemicolectomy with ileostomy formation.

Results The details of the resected tumour are given in table I below.

She was referred to Adult Colorectal Surgical and Oncology team and was started on adjuvant chemotherapy following MDT discussion.

Discussion Diagnosis of CRC in paediatric patients remains an incidental finding due to nonspecific symptoms and low level of suspicion. Therefore, it usually gets diagnosed at advanced stage and bears poor prognosis. Although CRC is more common in older adults its incidence is increasing in younger age group including <20-year olds. Mucinous adenocarcinoma comprises $>50 \%$ of all paediatric CRC and has a poor prognosis.

Conclusion Though CRC presents with non-specific symptoms in children and adolescents, this case is presented to raise awareness of its possibility. Input from the Adult Colorectal MDT is recommended for further management.

\section{P11 CHARACTERISTICS OF CHILDREN WITH INTUSSUSCEPTION IN PEUTZ-JEGHERS SYNDROME IN A SPECIALIST CENTRE OVER A 10 YEAR PERIOD}

${ }^{1}$ Vaia Zouzo, ${ }^{2}$ Claire Brooks, ${ }^{3}$ Claire Kulke, ${ }^{1}$ Elizabeth Renji, ${ }^{1}$ Fiona Cameron, ${ }^{1}$ Sarang Tamhne, 'Manjula Nair, 'Jeng Haw Cheng, ${ }^{1}$ Naima Malik, ${ }^{1}$ Marcus Kh Auth. ${ }^{1}$ Alder Hey Children's Hospital; 'Liverpool Women's Hospital; ${ }^{3}$ Birmingham Women's and Children's Hospital

\subsection{6/flgastro-2021-bspghan.22}

Introduction Children with Peutz-Jeghers syndrome (PJS) are at high risk of intussusception and bowel resection from small intestinal polyp formation. Little data has been published on early warning signs and prevention. We contributed to recent ESPGHAN guidelines, which recommend to start screening investigations from the age of 8 years in 3 -yearly intervals. In spite of meticulous endoscopic and imaging screening, three of our patients developed intussusceptions.

Aim

1. To identify patient characteristics and polyp features in PJS patients with intussusceptions compared to patients without this complication. 
2. To review if a more cautious surveillance protocol may be beneficial for children with PJS considered being at increased risk.

Subjects and Methods All patients were confirmed to have PJS by genetic analysis (STK 11 mutation).

Patient A underwent endoscopic surveillance every 2-3 years. At 9 years video capsule endoscopy (VCE) revealed one stalked small polyp and some areas of fresh blood in the small bowel, so double-balloon-enteroscopy (DBE) performed and two polyps removed. 4 years later the patient presented with sharp abdominal pain for two weeks associated with a mass in LIF, reduced appetite and required semi-urgent laparoscopic resection.

Patient B was diagnosed de novo at the age of 11 years due to lip and mucosal freckling. In addition to upper and lower GI endoscopy, small bowel imaging was booked but patient did not adhere to recommendations. Following pathological VCE, urgent booking for DBE was made but postponed by the family. The child presented then acutely with small bowel intussusception, underwent an urgent laparotomy and resection.

Patient $\mathrm{C}$ was diagnosed at the age of 8 years, presenting with anaemia, acute abdominal pain and non-bilious vomiting. An urgent ultrasound abdomen revealed small bowel intussusceptions, leading to laparotomy and resection. Intraoperative enteroscopy was performed with removal of two further polyps $10-15 \mathrm{~cm}$ from the resected bowel.

Results Review of 7 PJS patients without intussusceptions during the same 10 year period did not demonstrate significant differences in age of presentation, presence of polyps in stomach, or duodenum. Regarding small intestinal polyp formation, 2 of control patients had small intestinal polyps, one of them referred for $\mathrm{DBE}$ and the other one did not require DBE resection.

\section{Summary and Conclusion}

1. In our cohort of children with PJS, presence of small intestinal polyps was the only risk factor for intussusceptions. Intussusceptions occurred in 5/10 of all children with small intestinal polyps.

2. Dynamics of small intestinal polyps appear variable, but occurred earlier or in shorted intervals than recommended by ESPGHAN guidelines.

3. Although small bowel investigations can be difficult for some children with PJS, we recommend that they should be performed not later than 8 years of age. Due to absence of early warning signs for intussusceptions, if small intestinal polyps are found, small bowel imaging under optimal imaging conditions should be repeated annually and also immediately when children are symptomatic.

4. Centres are encouraged to enroll patients in the upcoming ESPGHAN polyposis group PJS registry.

\section{P12 CLINICAL CHARACTERISTICS, DIAGNOSIS AND MANAGEMENT OF EOSINOPHILIC OESOPHAGITIS: A RETROSPECTIVE CASE SERIES}

James Church, Taha Rasul, Rajiv Mohan, Hemant Bhavsar. Leicester University Hospitals NHS Trust

10.1136/flgastro-2021-bspghan.23

Abstract P11 Table 1 Characteristics of PJS patients with intussusceptions

\begin{tabular}{|c|c|c|c|}
\hline Patients characteristics & Patient A & Patient B & Patient C \\
\hline Age at diagnosis $(\mathrm{y})$; gender & 5.3 , female & 11 , female & 8.4, female \\
\hline Family history of PJS & Yes & No & Yes \\
\hline Age at Intussusception (y) & 15.7 & 12.9 & 8.4 \\
\hline Time since diagnosis $(\mathrm{y})$ & 10.3 & 1.8 & 0 \\
\hline $\begin{array}{l}\text { Last endoscopic assessment } \\
\text { (interval since presentation with } \\
\text { Intussusception) }\end{array}$ & $\begin{array}{l}\text { Endoscopy( } 6 \mathrm{mts}) \text { : } \\
\text { Stomach: } \times 50 \text { sessile polyps }(<8 \mathrm{~mm}) \text {, x1 sessile polyp } 10 \mathrm{~mm} \\
\text { Duodenum: } \times 10 \text { sessile polyps }(<5 \mathrm{~mm}) \\
\text { Colon: } \times 5 \text { sessile polyps in DC, sigmoid, rectum, } x 1 \text { stalked } \\
\text { polyp } 12 \mathrm{~mm} \text { in TC - snare polypectomy }\end{array}$ & $\begin{array}{l}\text { Endoscopy ( } 18 \mathrm{mts}) \text { : } \\
\text { Stomach: } x 1 \text { sessile polyp }(2 \times 3 \mathrm{~cm})-\text { not removed } \\
\text { as no inpatient bed available } \\
\text { Colon: no polyps }\end{array}$ & - \\
\hline $\begin{array}{l}\text { Previous Imaging (interval since } \\
\text { presentation with Intussusception) }\end{array}$ & $\begin{array}{l}\text { Barium meal and FT (2.2y): some filling defects in small bowel, } \\
\text { no large polyp } \\
\text { DBE (2y): no significant abnormalities in small bowel } \\
\text { VCE }(2.8 \mathrm{y}) \text { : small sessile polyps in jejunum and lleum } \\
\text { VCE }(8 \mathrm{~m}) \text { : normal - faecal loading }\end{array}$ & $\begin{array}{l}\text { MRE: planned but not performed as patient refusing } \\
\text { oral/NGT contrast } \\
\text { VCE }(4 \mathrm{~m}) \text { : small polyps in duodenum, slow transit } \\
\text { from duodenum to jejunum, polyps in proximal and } \\
\text { distal jejunum } \\
\text { DBE: urgent referral, not adhered to by family }\end{array}$ & - \\
\hline Imaging prior to surgery & $\begin{array}{l}\text { USS abdomen: Persistent small bowel intussusception in the } \\
\text { upper abdomen, the involved loops show peristalsis, not } \\
\text { significantly thickened }\end{array}$ & $\begin{array}{l}\text { USS abdomen: abnormal loop in central abdomen, } \\
\text { very suspicious of intussusception } \\
\text { CT abdomen: } \\
\text { Jejuno-jejunal intussusception (thickened wall, } \\
\text { proximal dilatation), large hamartomatous polyp in } \\
\text { ileum (filling defect) }\end{array}$ & $\begin{array}{l}\text { USS abdomen: Ileo-lleal } \\
\text { Intussusception }\end{array}$ \\
\hline Surgery & $\begin{array}{l}\text { 1. No intussusception identified } \\
\text { 2. } 2 \times \text { polyps }(1 \times 2 \mathrm{~cm}) \text { in mid lleum } 10 \mathrm{~cm} \text { apart from each } \\
\text { other }\end{array}$ & $\begin{array}{l}\text { 1. Jejunal small bowel Intussusception with polyp as } \\
\text { a lead point } \\
\text { 2. Necrotic bowel over } 100 \mathrm{~cm} \text { once reduced } \\
\text { 3. x5 polyps (max } 2 \times 1.7 \times 3.6 \mathrm{~cm} \text { ) }\end{array}$ & $\begin{array}{l}\text { 1. } x 2 \text { lleo-lleal Intussusceptions } \\
\text { each with a pathologic lead point } \\
\text { of a polyp } \\
\text { 2. } x 2 \text { polyps } 10-15 \mathrm{~cm} \text { from the } \\
\text { resected bowel removed }\end{array}$ \\
\hline Small bowel resection $(\mathrm{cm})$ & 15 & 100 & 45 \\
\hline
\end{tabular}

